MELISSA LIMA

CAMINHA
Escuela Universitaria ERAM (Centro adscrito a la Universidad de Girona) melissa.caminha@eram.cat

\title{
Hacia una risa posthumana y decolonial: Construyendo una risistencia feminista monstruosa en la payasaria.
}


TOWARDS A POST-HUMAN AND DECOLONIAL LAUGH: BUILDING A MONSTROUS FEMINIST LAUGHTERISISTANCE IN THE CLOWNERY.

\section{ABSTRACT}

In the last two decades, various female clowns have been developing a movement of visibility of this comic type, both in the circus and in the theater. Festivals, workshops and research have been contributing to write the doubly eccentric herstories of women in clowning. This honorable movement, however, still seems to follow the same archetypal logic of the modern clown, heir to the Enlightenment. This work values the female clown as a fundamental political body, with the potential to create plural laughters that can deconstruct the figure of the modern clown and the humanistic laugh embodied in its archetype. It recognizes the historical importance of female clowns, and invites a step forward in its artistic body politics, now from a feminist post-humanist and decolonial perspective, proposing artistic and theoretical coalitions in favor of a democracy of laughter. Through the creation of monstrous mobile feminist figurations, the project aims to encourage a movement of laughteresistance at modern, enlightened, colonial, humanistic, and patriarchal laughter.

\section{Keywords}

Female clowns; feminism; monster; laughterisistance; posthumanism; decolonial approach.

\section{RESUMEN}

En las dos últimas décadas, diversas payasas vienen desarrollando un movimiento de visibilización de este tipo cómico, tanto en el circo como en el teatro. Festivales, talleres e investigaciones vienen contribuyendo para escribir la historia doblemente excéntrica de las payasas. Este honorable movimiento, sin embargo, aun parece seguir la misma lógica arquetípica del payaso moderno, heredero de la llustración. Este trabajo pone en valor la payasa en tanto cuerpa política fundamental, con el potencial de crear risistencias plurales que puedan deconstruir la figura del payaso moderno y la risa humanista encarnada en su arquetipo. Reconoce la importancia histórica de la payasa, e invita a seguir avanzando en sus políticas artísticas del cuerpo, ahora a partir de una perspectiva feminista posthumanista y decolonial, proponiendo políticas de coaliciones artística y teórica en pro de una democracia de la risa. A través de la creación de figuraciones feministas móviles monstruosas, el proyecto tiene como objetivo animar un movimiento de risistencia a la risa moderna, ilustrada, colonial, humanista y patriarcal.

\section{Palabras Clave}

Payasas; feminismo; monstruo; risistencia; posthumanismo, perspectiva decolonial. 
El payaso moderno se ha configurado como el principal arquetipo de la risa y la comicidad. Heredero de la tradición humanista, patriarcal y antropocéntrica de la llustración, se ha forjado como persona cómica creada a partir de la subjetividad del propio artista. La nariz roja es conocida como la menor máscara del mundo, pero "la que más revela". Revela exactamente el yo y self del artista. La diferencia entre un actor teatral y un payaso, por ejemplo, reside en que el primero pone la máscara del personaje para interpretarlo. El payaso, al contrario, quita las máscaras sociales para representar a sí mismo (Caminha, 2016).

Esta investigación empieza con un estudio sobre los discursos y prácticas en torno a la construcción de la subjetividad en el "mundo clown". Discursos y prácticas herederos del humanismo y la Ilustración. En seguida, propongo una deconstrucción de lo humano que rescata las tradiciones, genealogías y cuerpos monstruosos, desterrados del concepto de humanidad y marginalizados de la historia del circo y de la payasaria moderna. Una deconstrucción de una humanidad que es, a la vez, antropocéntrica, colonial y patriarcal.

Este proceso de deconstrucción del clown moderno ya ha empezado con el movimiento de payasas de las últimas dos décadas. A través de numerosos festivales, cursos e investigaciones, las payasas vienen escribiendo una nueva historia del circo, de la payasaria y de esta figura cómica, deconstruyendo la tradición patriarcal en la payasaria.

Mientras la intervención feminista en la Historia del Arte empieza en las décadas de los 60 y 70 , la profesionalización de la payasa solo ocurre a partir de los 80 . Pero una conciencia organizada del valor histórico, cultural, pedagógico y político de este tipo cómico empieza en 2011, cuando la payasa catalana Pepa Plana organiza el primer Festival de Pallasses de Andorra. Era el inicio de un movimiento que se viene difundiendo por Europa y Latino América, a través de festivales, cursos, encuentros e investigaciones dedicadas a legitimar, conocer y fomentar la comicidad de la mujer a través de la figura de la payasa. Después del primer festival en Andorra, diversas mujeres siguen tocando el movimiento:

\begin{tabular}{c|c|}
\hline Festivales & País \\
\hline Festival de Comicidade Femenina - Esse Monte de Mulher Palhaça & Brasil \\
\hline Clownin - International Women's Clown Festival & Austria \\
\hline Red Pearl & Finlandia \\
\hline Palhaçaria - Festival de Palhaças do Recife & Brasil \\
\hline Encontro de Palhaças de Brasília & Brasil \\
\hline Ciclo de Mulheres Palhaço - Chapitô & Portugal \\
\hline Bolina - Festival Internacional de Palhaças & Azores \\
\hline Vabieka - Festival Internacional de Palhaças & México \\
\hline Ciclo Very Important Women - Almazen & España \\
\hline Trobada de Dones Pallasses - Casa de la Dona & España \\
\hline Festival de Pallasses - Circ Cric & España \\
\hline
\end{tabular}

Figura 1. Encuentros de payasas. Elaboración propia. 
Este proyecto de visibilización también ha sido acompañado en la academia. Solo en Brasil, donde hay un fuerte movimiento de payasas mujeres, diversas investigaciones vienen reflexionando sobre las particularidades de este tipo cómico, tales como: Santos (2014), Nascimento (2014), Junqueira (2012), Saavedra (2011), entre otras.

El movimiento de payasas tomó cuerpo con la reivindicación de una categoría particular, la "comicidad femenina", que opera como estrategia de contra-producción de una "comicidad masculina", supuestamente performadas solo por mujeres y hombres, respectivamente. Esta idea de feminidad y masculinidad, basada en una concepción esencialista de la diferencia sexual, se olvida de las masculinidades y feminidades alternativas producidas en cuerpos inapropiados. La restricción a una categoría genérica esencialista de la diferencia sexual, fuertemente vinculada al ideal ilustrado de lo humano, no da cuenta de la multiplicidad de cuerpos no normativos y genealogías disidentes tan necesarios para un proyecto crítico, creativo y genealógico. Todo indica que parte de este proyecto de las mujeres payasas aún se encuentra atrapado en concepciones esencialistas en torno al sexo, género y a las concepciones eurocéntricas humanistas del sujeto ilustrado. Así que nos cabe repensar la comicidad de las mujeres no como una comicidad femenina única, relacionada con una Mujer supuestamente universal, sin sus diferencias étnicas, culturales, de clase, de orientación sexual y de racialización, sino comicidades plurales de mujeres, en su gran diversidad de formas, feminidades, masculinidades, experiencias, cuerpos, animalidades, monstruosidades, cosmologías y tecnologías.

Cabe apuntar, sin embargo, que, en los últimos cinco años, muchas mujeres están haciendo una deriva, de una "comicidad femenina" para una "comicidad y payasaria feminista". La cuarta ola feminista ha sacudido también el "mundo payasa", y si antes muchas artistas del clown y del circo no se atrevían a asumirse como feministas, ahora sí lo hacen, y cada vez más buscan dialogar e incorporar perspectivas críticas en sus discursos, pedagogías y performances. Necesitamos avanzar mucho en este sentido, para poder transformar nuestras políticas democráticas de la risa.

Este trabajo busca contribuir a una actual reflexión sobre el rol político de payasos y payasas en la contemporaneidad, en sus actuaciones artísticas e intervenciones socio-educativas. Indaga acerca del origen blanco, falo y euro céntricos de la estética y poética del clown moderno, que parece orientar y homogenizar gran parte del imaginario de la payasaria contemporánea. Busca permitir, rescatar, reconocer y legitimar otras formas de reírse. Replantea y reconsidera la lógica metafísica de construcción del sujeto moderno, y consecuentemente del clown moderno, y sus conceptos en torno del yo y del self, por tanto, de este personaje-persona cómica egocéntrica. Considera la comicidad tanto en su potencial subversivo como en su riesgo de mantenimiento del status quo. Cuestiona cómo, cuáles performances y cuáles cómicos son legitimados como payasos y payasas, y en qué contextos son legitimados a actuar.

Otro objetivo es invitar a payasos y payasas a salir de la endogamia del "mundo clown", para establecer contactos y coaliciones con diversas prácticas artísticas, activistas y teóricas, articulándose políticamente y fomentando redes deconstructivas del sujeto colonial humanista. Estas relaciones ya vienen siendo establecidas dentro del circo, en lo que se viene construyendo como Circus Studies ${ }^{1}$ a nivel internacional. Considero que el movimiento de payasas mujeres de Iberoamérica, especialmente Latino América, tiene mucho a contribuir para descolonizar el circo y la payasaria en este panorama internacional de indagaciones sobre Circus and Its Others $^{2}$, y por supuesto, también a nivel local. 
Este trabajo es fruto de mi experiencia de más de 15 años como payasa, bien como de mi investigación doctoral, titulada Payasas, realizada en el posgrado de Artes y Educación, Facultad de Bellas Artes, Universidad de Barcelona (Caminha, 2016). Como payasa investigadora pude participar en innúmeros cursos de clown, además de festivales y encuentros en Brasil y España. Al indagar por el payaso en tanto arquetipo, pude darme cuenta de cómo esta figura cómica logró constituirse como un excéntrico socialmente legitimado a actuar en diversos espacios, más allá del circo y del teatro. Hoy día, varios son los payasos que actúan como educadores sociales, mediadores, terapeutas y "doctores payasos" ${ }^{3}$. Pero gran parte de este proceso de legitimación social de este tipo marginal y excéntrico se debe a que la figura ha pasado por un proceso de aburguesamiento, un proceso civilizatorio y una cierta "higienización" de sus elementos grotescos y monstruosos.

La metodología desarrollada en este trabajo consta, primeramente, de revisión bibliográfica y documental, con vistas a la deconstrucción de este tipo cómico. En seguida, y como parte de este proyecto que es a la vez crítico y creativo, propongo figuraciones móviles encarnadas y monstruosas, inspiradas y nutridas por el arte, performance y teorías feministas posthumanas y decoloniales. La figura del monstruo (Balza, 2012) funciona como catalizador de puntos de encuentro entre prácticas discursivas, teóricas, performativas y artísticas que se nutren de un proyecto común de "risistencia" al concepto de humano, o sea, de una re-existencia (AlbánAchinte, 2018) a través de la risa creativa, que se alimenta de una energía propositiva para la creación de nuevos mundos posibles a través del arte y de lo sensible. La figura del monstruo sirve como impulsor que invita a reunir cuerpos históricamente desubicados de la condición humana tal como forjada por el proyecto colonial de la modernidad ilustrada, celebrando otras risas posthumanas y decoloniales. La risa monstruosa se ubica dentro de una perspectiva

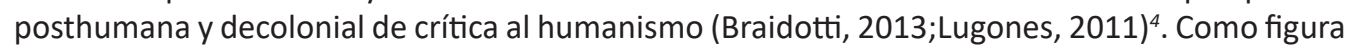
por excelencia que desafía las normas, formas y los límites entre humano-animal-máquinanaturaleza, el monstruo se reclama en este trabajo como artesano de intra-relaciones y coaliciones entre sujetxs, risas y cuerpos monstruosos.

Antes de adentrar en el cuerpo del texto, me gustaría posicionarme como mujer brasileña, blanca de clase media, migrante, madre, payasa, educadora e investigadora feminista en eterna formación. Con esta breve presentación, busco atender a una política de conocimiento situado (Haraway, 1985), de localización (Rich, 1984) y de interseccionalidad (Collins, 2000; Crenshaw, 1995; Nash, 2019), para tal de facilitar a Ixs lectorxs una mejor comprensión de la experiencia desde dónde hablo. Como feminista en formación, me encuentro en un proceso de investigación de la blancura de mi currículo y de mis referentes, tanto artísticos como académicos. De ahí mi deseo de avanzar hacia una política feminista decolonial, ya que el feminismo, si no es decolonial y anti-capitalista, no puede reivindicarse como feminismo. Este proyecto se constituye en movimiento, en potencia y en deseo de abrir ventanas de diálogos, conexiones, afectos y cuidados. Un proyecto que apenas empiezo a gestar, ya que las semillas plantadas en mis estudios de doctorado desean ser regadas de forma colectiva a través de la creación de coaliciones risistentes entre artistxs, teóricxs y activistxs. 
2 El payaso moderno: Arquetipo liminal y encarnación de la risa humanista.

El payaso, tal y cómo se nos presenta hoy en el circo, teatro, fiestas y performances diversas, se ha construido a partir de múltiples referentes históricos y culturales. Referencias provenientes de diversos ámbitos disciplinares, como la antropología, los estudios de teatro y de performance. El payaso moderno está relacionado con una gama de figuras excéntricas, marginales y liminales, tanto en el ámbito artístico como social, en diferentes épocas históricas y localidades geográficas. El payaso encuentra en su genealogía referencias como el chamán de diversas tribus indígenas de todos los continentes, bien como tricksters, bufones, bobos de las cortes reales, artistas de la comedia dell'arte italiana, del circo, del teatro de variedades, de cabarets, del Teatro Shakesperiano, y figuras cómicas de manifestaciones de la cultura popular de pueblos diversos.

Algunos autores ya se ocuparon de hacer comparaciones, describir similitudes antropológicas y trazar supuestos universales entre estas figuras, con diversos planteamientos de carácter técnicoartístico, filosófico-religioso, psicológico-medicinal y socio-político. John Towsen (1976), para citar un ejemplo, en su obra Clowns: Panoramic History of Fools and Jesters. Medieval Mimes, Jongleurs and Minstrels. Pueblo Indian Delight Makers and Cheyenne Contraries. Harlequins and Pierrots. Theatrical Buffons and Zannies. Circus Tramps, Whitefaces and Augustes, evidencia la herencia moderna y antropológica que categoriza ciertas tipologías y figuras liminales como clowns. En este trabajo, Towsen hace una larga presentación de las innúmeras nomenclaturas, taxonomías y características de tipos sociales y artísticos que guardan similitudes estéticas y conceptuales con lo que hoy es comprendido por la palabra clown o payaso. Y las relaciones que se establecen entre muchos tipos tienen que ver con los diversos rituales antropológicos y sus propiedades liminales, mediados por la risa y la comicidad instaurada por el payaso en tanto arquetipo mediador de estos ritos. Por tanto, uno de los elementos constituyentes de estos tipos, es lo que os une como entidades estéticas, poéticas y sociales que actúan como instauradores del "mundo al revés".

Mundo al revés es una categoría utilizada por teóricos estructuralistas para describir el estado de comunión instaurado en diversas tribus y sociedades primitivas, modernas y contemporáneas, a través de rituales, festividades y eventos. Se describe como un mundo al contrario porque opera la inversión temporaria de valores, jerarquías, posiciones y relaciones de poder, haciendo que una realidad o mundo alternativo pueda existir de forma temporal (Turner, 1982, 1988; Bakhtin, 2002; Davis, 1978).

El mundo al revés es considerado como potencialmente transformador del status quo, ya que en él se permite experimentar posibilidades de ser y estar en el mundo de forma diferente, por tanto, de construir mundos diferentes. Como en las fiestas y carnavales de Bakhtin (2002) - autor de referencia para muchos payasos y payasas -, en el mundo clown las jerarquías son supuestamente rotas y una especie de comunión se pretende instaurada, lo que Turner (1982, 1988) llama comunitas.

El mundo al revés de los payasos promete a sus "ciudadanos" una existencia libre de los dictados de una moral represora. En muchos rituales de iniciación en la identidad clown, los aprendices son guiados a romper con las máscaras sociales y presentarse como son "de verdad, en su esencia y pureza", por así decirlo. Como explica el actor brasileño Ricardo Puccetti, payaso Teotônio, la nariz roja es considerada la menor máscara del mundo, pero la que más revela 
(Puccetti en Caminha, 2006). Apoyada en algunas teorías de la risa y de la comicidad, la máscara clown busca un efecto inverso, de un "demascaramiento", tal como sugieren los filósofos Henri Bergson (2004) y Vladimir Propp (1992). Demascaramiento fuertemente vinculado a una propiedad expresiva y a una concepción esencialista del sujeto.

Al elaborar tipologías de risa según varios aspectos de análisis, Propp (1992) sugiere que la risa burlona es aquella que más se encuentra en la vida y en el arte, y que está relacionada al demascaramiento, súbito e inesperado, de defectos ocultos, sean estos de carácter físico o moral. Bergson (2004), a su vez, también hace referencia a este proceso de demascaramiento, a partir de la ridiculización y del constreñimiento que genera la risa, que operan como una especie de burla social, que corrige y pune la sociedad de sus defectos. Según Bergson, "La risa castiga las costumbres. Nos hace parecer ser inmediatamente lo que deberíamos ser, lo que sin duda acabaremos por ser de verdad" (2004, p.13). La risa, vinculada así a este mecanismo de demascaramiento, se encuentra relacionada con una propiedad expresiva, de revelación o descubierta de una sustancia, esencia o verdad que se intenta encubrir o mascarar en la vida social.

En el ámbito de la formación artística y del proceso de creación de la persona cómica del payaso, el demascaramiento pasa a ser comprendido como la búsqueda de la sustancia de uno mismo misma, del verdadero self del artista. Un desvelamiento articulado desde ejercicios escénicos que entrenan la espontaneidad de la acción del aprendiz. La "honestidad" y "sinceridad" de la actuación del performer funcionan como categorías para valorar su "autenticidad, personalidad y originalidad" (Caminha, 2016).

Entrenar el estado clown está relacionado con la espontaneidad del cuerpo, en una acción genuina, auténtica y representativa de la pureza, originalidad y esencia de cada uno/una. Aunque haya una confusión entre el "estado clown" y el "ser clown", parece prevalecer esta última condición ontológica. La persona cómica del payaso se crea a partir del desvelamiento del supuesto verdadero yo del artista, sin máscaras, sin fingimientos, de una persona desnudada, "natural". Ser payaso o payasa pasa a ser una actitud afirmativa de la identidad clown, y de la subjetividad original y primaria de uno mismo, como representación del verdadero self, de una persona pre-discursiva, existente fuera del lenguaje y de la cultura, transcendental. De ahí que muchos pedagogos y maestros clown utilicen las metáforas del niño, del primitivo, del viejo y del loco, para inspirar a sus aprendices a buscar "el payaso que cada uno lleva dentro". El clown pasó, en fin, a ser un vehículo para corporizar la metafísica y transcendencia de la personalidad. Este proceso de psicologización del payaso, a través del cual el artista no representa ni interpreta un personaje, pero pasa a serlo y vivirlo en la vida y en el arte, como una expresión genuina del yo, se encuentra elaborada y apuntada por muchos artistas y autores contemporáneos, desde el Renacimiento hasta nuestros días.

Ya en referencia a los primeros clowns del teatro isabelino del siglo XVI, David Wiles (1987) así se refiere al actor inglés Richard Tarlton, considerado por muchos historiadores, el primer payaso: "Está claro, entonces, que ninguna distinción absoluta se puede hacer entre Tarlton el hombre y los papeles que desempeñó en diferentes entornos (...) Esta fusión del hombre y su papel es una cualidad que los sucesores de Tarlton iban a retener" $\left(1987\right.$, p.16). ${ }^{5}$

Luego, Arlequín y Pierrot vendrían a representar el alter ego de muchos artistas e intelectuales modernistas europeos. De hecho, los representantes emblemáticos de la commedia dell'arte pasaron a ser tema y motivo pictórico recurrente en las artes visuales (Watteau y Picasso), artes 
escénicas (Deburau, Diaghilev), música (Schoenberg, Stravisnky), poesía (Baudelaire y Laforgue) y cine (Chaplin), como apuntan algunos ejemplos de Martin Green y John Swan (1986).

Posteriormente, las figuras del clown de cara blanca y el payaso augusto, consagradas en el circo clásico, vendrían a componerse basándose en la personalidad y en la lógica individual de cada artista, así como en sus características físicas y corporales (Burnier, 2001; Jara, 2007; Ferracini, 2003; Peacock, 2009; Bolognesi, 2003).

El poeta Laforgue, probablemente como otros tantos artistas de su época y de la actualidad, decía identificarse con todos los pierrots y clowns. En 1882, escribió a un amigo: "¿A ti no te encanta el circo? Acabo de pasar cinco noches consecutivas allí. Los payasos me parece que han llegado a la verdadera sabiduría. Yo debería ser un payaso, pero he perdido mi verdadera vocación" (Green y Swan, 1986, p.27).

La fascinación por la figura del clown parece estar relacionada con una creencia de que este tipo cómico tiene la capacidad de representar la humanidad perdida de una sociedad corrompida por valores inhumanos. "En 1932, Pierrot encarnó al artista, a todos los artistas, en toda la humanidad, fue el héroe emblemático de la sensibilidad" (Green y Swan, 1986, p.9).

En el siglo XX, con la llegada del Nouveau cirque y con la creación de las primeras escuelas de circo, las disciplinas circenses pasaron a ser enseñadas a diversos artistas y pedagogos de teatro - como Jacques Lecoq, Philippe Gaulier, LUME Teatro, entre otros -, que eligieron el payaso como una especie de disciplina artística, justamente porque su entrenamiento proporciona al performer el descubrimiento de las potencialidades individuales, únicas y singularidades de uno mismo. El maestro francés Jacques Lecoq (2009) ha tenido una particular influencia en la diseminación de una pedagogía clown basada en la máscara. Su famosa escuela ha adoptado la nariz roja como una de las principales máscaras de su programa de formación de actores, siendo responsable de la formación de innúmeros payasos y payasas en las últimas décadas.

La búsqueda del "clown psicológico" o "clown personal", como así lo denominan los artistas del grupo LUME (Ferracini, 2003; Burnier, 2001) - como herencia de la pedagogía de Lecoq -, pasó a ser una referencia no solamente para actores que desean ser payasos profesionales, sino también para artistas que en general buscan enriquecer su performance escénica desde el descubrimiento del propio ridículo, de su humanidad latente que vibra bajo la armadura de la insensibilidad impuesta por una sociedad injusta y desigual. Como nos explica Luís Otávio Burnier, fundador del grupo LUME, iniciador de la pedagogía clown heredera de Lecoq, en Brasil:

El clown es la exposición del ridículo y de las debilidades de cada uno. Por lo tanto, es un tipo personal y único. Una persona puede tener tendencias para el clown blanco o el clown augusto, dependiendo de su personalidad. El clown no representa, él es (...) François Fratellini, miembro de la tradicional familia de clowns europeos, decía: "En el teatro los comediantes fingen. Nosotros, los clowns, hacemos las cosas de verdad" (Burnier, 2001, p.209).

La lógica expresionista y los posibles efectos terapéuticos del arte clownesco, derivados de un abordaje psicológico del sujeto, también constituyen ejes de principios y prácticas de clown terapia, intervenciones pedagógicas y educación social. Innúmeros son hoy día los payasos, profesionales de la salud y educadores sociales que se sirven de la risa clownesca para realizar intervenciones sociales en los más diversos contextos, tales como hospitales, zonas de conflictos, 
comunidades en vías de desarrollo cultural, centros de detenciones, escuelas, iglesias, entre otros espacios.

En los muchos cursos y talleres de formación de clowns, sea en contextos de formación artística como de intervención terapéutica y comunitaria, aún es posible encontrar una cierta promesa de rescate de la humanidad perdida u olvidada, a través del encuentro con el "payaso que cada persona lleva dentro de sí", para utilizar expresiones provenientes del mundo clown.

Pero esta lógica expresionista y humanista del clown contribuyó, en cierta manera, a distanciar el arquetipo de sus relaciones ancestrales con lo grotesco, lo deforme y lo monstruoso. Esta distancia es uno de los conflictos existentes entre el circo y el teatro, apuntados por el investigador brasileño Mario Fernando Bolognesi (2006).

En una comparación con el proceso de aburguesamiento que Arlequín y demás máscaras de la commedia dell'arte italiana sufrieron en Francia, Bolognesi explica que el payaso pasó por algo similar al ser apropiado por el teatro. Según el investigador, con la apropiación del arte del clown por el teatro, el payaso pasó por una especie de proceso civilizador, de naturalización y verosimilitud, por medio del cual el clown se encaja en los moldes de la escena y dramaturgia contemporáneas, y también en el "juego del espíritu y del intelecto". Para el autor, el payaso abandonó el principio épico-comunicativo, propio del circo, para adoptar "una postura dramática, expositora de una individualidad exclusiva" (Bolognesi, 2006, p.15).

En una clara referencia a la idea del clown más teatral, como artista que trabaja el "ridículo personal", Bolognesi comenta: "el conflicto (que remite a la orden social y psicológica), fue suprimido en nombre de una expresividad escénica que exalta el ridículo aceptable. En otras palabras, ese proceso internaliza, en el dominado, la voz del dominador". Y sigue:

El clown, tal como ha sido apropiado y desarrollado en la mayoría de los grupos y artistas de teatro, se transformó en figura emblemática y poética, portadora de una poesía propia, esencialmente etérea. Esta tendencia enfatiza lo gracioso, en detrimento de lo grotesco; invierte en la ironía, debilitando la sátira y la parodia. En pocas palabras, este prototipo de clown pasó por un profundo proceso de subjetivación e individualización, llegando a abandonar las características cómicas grotescas que lo consagraron. Las marcas del cuerpo (el cuerpo es el "alma del payaso"), subyugado a la autoridad y al orden, privado del alimento, del amor y del sexo, están aún más escamoteadas (Bolognesi, 2006, p. 15).

Este proceso de teatralización del payaso, también lo aproximó a una estética del realismo y naturalismo. Un proceso que también se dio en el cine y el circo soviético. Chaplin y otros payasos del cine, como El Gordo y el Flaco y Pat und Patachon, inspirarían una especie de culto al realismo y al naturalismo del clown moderno, que influenciaría toda una estética y poética política en la escuela de circo soviética. Esta nueva tendencia, encarnada en las performances de clowns como Karandash, los hermanos Durov y Oleg Popov, vendría a establecer toda una crítica al payaso del circo y a la figura del bufón tradicional europeo. Este nuevo payaso político se distanciaba de una estética de lo grotesco y de lo exceso, aproximándose de una poética que mezclaba naturalidad y absurdidad. El elemento político dejaba de vincularse al espectáculo corporal de la diferencia, bien como de la parodia encarnada, para aproximarse a una sátira política actualizada y directa, de payasos más realistas y comprometidos con los acontecimientos de su época. Para los payasos rusos, la "sátira incorporada" en lo grotesco debería sustituirse por una sátira naturalista que operase mediante la absurdidad de los gestos y acciones, bien 
como de un discurso y compromiso político directo con los temas de la época.

El viejo estilo de payaso, con técnicas y principios de construir un acto, y el siempre presente "bufón" se está acabando, principalmente porque la audiencia quiere ver a un hombre vivo y natural. La aparición de degenerados, paralíticos, idiotas, maníacos y otras formas de demencia (y esta es la base psicofísica de todos los tipos de "bufón") ya no puede mantener el interés de la audiencia soviética. De hecho, ¿cuántos de esos "payasos", invariables en sus tradiciones, y tradicionales en su naturaleza inmutable, se parecen a una persona viva? Es imposible compararlos con cualquier ser humano... (Tanti en Popov, 1967, pp. 54-55).

El payaso ruso Oleg Popov hace referencia a esta cita de Tanti para explicar por qué ha decidido adoptar el enfoque realista. El realismo y el naturalismo pasaron a integrarse a la propuesta de la sátira política de varios clowns rusos. Un realismo y naturalismo que, tanto en el ámbito de la pedagogía clown como de la creación de la persona cómica del artista, se inclina por un ideal de humano y humanidad, en un proceso que de cierta manera acabó por excluir y marginalizar diversos cuerpos y formas marcadas por la diferencia corporal.

Ilya Fink (1958), al hablar de Karandash y su performance política, también hace hincapié en el realismo absurdo y satírico del gran clown ruso, realismo este "copiado" de famosos clowns del cine, como una crítica a la pura sátira incorporada de los viejos clowns y bufones. "En busca de nuevos medios de expresión, los payasos comenzaron a copiar comediantes de películas extranjeras tan populares como Pat y Pataschon y Charlie Chaplin" (Fink, 1958, pp. 63-64).

Algunos enfoques de la escuela soviética de clowns revelan el ideal activista de varios payasos que comprenden lo social y lo político como extremamente vinculados al realismo y al naturalismo. Y esto, traducido a la pedagogía y a la creación de la persona cómica, acaba configurándose en el supuesto realismo y naturalismo de uno mismo, la expresión genuina de la subjetividad e individualidad del artista. Un naturalismo heredero de los ideales modernos humanistas ilustrados, que conciben el sujeto como entidad autónoma, original, sustancial y natural.

Ya habiendo reconocido el gran potencial terapéutico y pedagógico que el arte del payaso puede proporcionar a un nivel personal para artista, público y paciente (Caminha, 2006), en este trabajo el foco está dirigido a las construcciones sociales que hacen del payaso el principal representante y arquetipo central de una comicidad patriarcal, humanista e ilustrada. El ideario romántico, poético y humanista acabó de cierta manera excluyendo, invisibilizando, o silenciando la marca corporal de la diferencia, generando espacios marginales que creo deben ser rescatados por el mundo clown, de forma a recuperar sus referencias cómicas y paródicas, y no someter la performance e intervención clownesca a los dictados del "gran y respetable público"6: heteronormativo y patriarcal, sediento de un humanismo ilustrado incorporado por el anti-héroe de la modernidad: el payaso.

El discurso ilustrado de muchos payasos, y más recientemente también de algunas payasas del mundo clown, contribuye a mantener esta figura cómica enganchada al ideario modernista del arte y de la ciencia, y sus pretensiones de representar un sujeto universal, pero ahora en el ámbito de la comicidad, del mundo al revés, sus principios, construcciones y arquetipos. De hecho, el payaso es considerado por muchos artistas como el principal arquetipo del mundo cómico, y "uno de los fundamentos del arte" (Adorno, citado en Pavis, 2005). De acuerdo con 
el payaso brasileño Marcio Libar, "La función del payaso, como principal arquetipo del mundo cómico, es instaurar el mundo al contrario. ¡Es hacer valer el mundo al revés!” (Caminha, 2006, p.25).

Pero como principal arquetipo y símbolo de la risa y de la comicidad, el payaso crea en torno de sí, desde sus espacios mediáticos, performativos y discursivos, un centro de visibilización privilegiado, bien como zonas de marginalidades. Excentricidades cuya apreciación considero esencial para una nueva comprensión de la comicidad y de la risa en la payasaria.

3 Hacia una risa posthumana y decolonial: La payasa monstruo y otrxs cuerpxs risistentes.

En su obra The Posthuman, Rosi Braidotti (2013) explica el poshumanismo como condición y posibilidad de vida más allá del Self y de las especies. El sujeto cartesiano, que en una perspectiva humanista ilustrada está al centro del mundo y de la vida, es desplazado por la idea de afecto, relaciones, comunidad, cosmos, zoe. La autora utiliza como ejemplo del humanismo clásico y romántico el hombre vitruviano de Leonardo da Vinci, un ideal que representa lo humano en su forma física, e instituye una norma de civilidad y ciudadanía basadas en el antropocentrismo y el Eurocentrismo. En este sentido, el sujeto posthumano deconstruye la ilusión de autonomía, independencia y excepcionalidad del ser humano, materializándose en y por las relaciones que se establecen entre todos los agentes, humanos y no humanos, que habitan el planeta y el cosmos.

Defino al sujeto critico posthumano a través de una eco-filosofía de pertenencias múltiples, como sujeto relacional determinado en y por las multiplicidades, que quiere decir un sujeto en condiciones de operar sobre las diferencias, pero también internamente diferenciado, y sin embargo, aún arraigado y responsable. La subjetividad posthumana expresa una forma de responsabilidad encarnada e integrada y, por lo tanto, parcial, basada en un fuerte sentimiento de colectividad, relacionalidad y, por tanto, de construcción de comunidad (Braidotti, 2013, p.49).

Claro está que el posthumanismo defendido por Braidotti bebe de las diversas concepciones cosmológicas del mundo y de la vida presentes en la perspectiva decolonial, que por su vez busca poner en evidencia las relaciones intrínsecas entre humanismo, modernidad y colonialidad. A pesar de sus diferencias, y de acuerdo con Winnubst (2019), tanto el posthumanismo como la crítica decolonial comparten un punto de partida común, a saber, la demanda para ir más allá de la figura de lo humano.

Las perspectivas coloniales y humanistas están firmemente arraigadas en epistemologías de la modernidad, que surgieron en contextos europeos. Sus ideales eran (y todavía son) excluyentes, ya que a lo largo de la historia los considerados completamente humanos fueron individuos occidentales, blancos, varones, heterosexuales, sin discapacidad y de clase alta solamente; es decir, estos dos marcos de referencia son eminentemente jerárquicos (Sousa y Pessoa, 2019, p.525).

Es a partir de este hilo común entre las perspectivas posthumanistas y decoloniales que el monstruo emerge con un gran potencial para catalizar afectos y afinidades disidentes. El monstruo, tal como nos recuerda la filósofa Isabel Balza (2012), es la representación histórica por excelencia de todo que no se encuadra en el concepto de humano. La humanidad ha sido 
definida por el hombre varón europeo a partir de la otredad. Y siendo el hombre blanco el sujeto de conocimiento de la filosofía y la ciencia occidental, es, por tanto, la norma, lo normal, tanto en términos físicos y biológicos como en términos de humor y comportamiento.

La categoría de monstruo engloba todo aquello desterrado del concepto de humano. El monstruo se define como categoría de exclusión social, como seres que se hallan en el límite de la humanidad, seres que se han considerado históricamente como inhumanos o no humanos. Todo aquello que se diferencia en mayor o menor grado del hombre blanco occidental es por lo tanto anormal, deforme, sub-humano, animal, materia inorgánica, extraterrestre, sobrenatural, materia inanimada y máquina. Así que la mujer, al lado de varias entidades vivas, no vivas y ficcionales, es un otro monstruoso, o mejor, una otra monstruosa, necesaria para que el hombre varón se defina, se construya y se realice como tal. A lo largo de la historia, las mujeres han sido constantemente excluidas del concepto de humano. Aristóteles (1994) ya consideraba a la mujer como desviación monstruosa, por ir en contra de la norma de la naturaleza: el varón. En su obra Reproducción de los animales, el filósofo ya consideraba a la mujer como ser mutilado, deforme o malformado.

Braidotti (1996) explica como la ciencia de los monstruos, la Teratología, se ha configurado como un conjunto de discursos organizados científica y socialmente sobre las diferencias corporales, y de cómo estos discursos se articularon a partir de los mecanismos de sexismo. Siguiendo a Kristeva (1980), Braidotti menciona la abyección como efecto de la reacción tanto al cuerpo de la mujer como al cuerpo monstruoso. Y es que Kristeva comprende lo abyecto a partir de un conjunto de emociones ambivalentes que van desde la fascinación y la adoración al miedo y al terror frente al cuerpo maternal. Sus fluidos corporales, sus humores y su deformidad provocan, según la autora francesa, fascinación y atracción, al mismo tiempo que miedo, asco y rechazo. La mujer, tratada como un cuerpo abyecto y grotesco, es la otra monstruosa, que se diferencia sexualmente del hombre varón: la norma de lo que es humano.

Los procesos de racialización también se encuentran en el centro de la Teratología. Según Braidotti, uno de sus discursos dominantes ha sido el de las razas monstruosas de los límites de la civilización. Así que en la antigüedad ya se observa una geografía antropológica, el estudio de territorios y tierras especiales dónde viven estas razas monstruosas. Canonizadas por obras de historia natural, estas razas monstruosas vendrían a tornarse parte del folclore medieval de Europa. Este imaginario racista de carácter geográfico y antropológico también está presente en la Política de Aristóteles, un ejemplo de que, según Braidotti, la cultura occidental ha tenido la tendencia de representar lo más lejano como el más monstruoso (Braidotti, 1996).

Esta Teratología colonialista ha hecho de toda especie lejana objeto de entretenimiento popular, como los freak and sideshows de los circos y ferias de los siglos XVIII y XIX, bien como de los zoológicos humanos (Pedraza, 2009; Thompson, 1996). Una versión contemporánea de estas razas monstruosas la encontramos hoy, aún de acuerdo con Braidotti, también en las obras de ciencia ficción sobre extraterrestres y alienígenas monstruosos, bien como en la concepción monstruosa de los judíos que ha sido manipulada de forma cruel por los nazistas. Procesos de racialización también aplicados a africanos, asiáticos y americanos.

Dentro de una perspectiva feminista decolonial, el sexismo y el racismo son analizados como procesos intrínsecos al proyecto colonial. María Lugones (2011) nos explica como la modernidad colonial está cimentada por una dicotomía central jerárquica entre lo humano y lo no humano, que por su vez está íntimamente relacionada con los conceptos engendrados de hombre y mujer. 
Es lo que la autora denomina colonialidad del género ${ }^{7}$. Este dimorfismo sexual se convirtió en la base para la comprensión dicotómica del género, que a la vez configura lo humano. Para Lugones, el sistema moderno colonial de género conforma la deshumanización, constitutiva de la colonialidad del ser.

La dicotomía jerárquica como marca de lo humano también se convirtió en una herramienta normativa para condenar a los colonizados. Las conductas de los colonizados y sus personalidades/almas eran juzgadas como bestiales y por lo tanto no-generizadas, promiscuas, grotescamente sexuales, y pecaminosas. Aunque en este tiempo la comprensión del sexo no era bimórfica, los animales se diferenciaban entre machos y hembras, siendo el macho la perfección, la hembra la inversión y deformación del macho. Los hermafroditas, los sodomitas, las viragos y los colonizados todos eran entendidos como aberraciones de la perfección masculina. (Lugones, 2011, p.107)

Vemos, por tanto, que la condición monstruosa responde a mecanismos sexistas y racistas, y por tanto, también al proyecto colonial de la modernidad, que marca como monstruoso todo cuerpo que se distancia del ideal masculino blanco y eurocéntrico, o sea, que marca a todxs cuerpxs no normativos, como los cuerpxs queer ${ }^{8}$, tullidxs, subalternxs, racializadxs y colonizados, gravados como raros, extraños, desviados, mutilados, enfermos, inferiores, animalizados, esclavos. Y es en este denominador común marcado por la monstruosidad que emerge la necesidad de formar coaliciones y políticas de colaboración que atiendan a diversos cuerpos monstruosos. Políticas que indaguen sobre la violencia de todo sistema normativo. Una violencia relacionada con las normas del sistema moderno colonial de sexo-género, de la heterosexualidad compulsoria, del capacitismo y de la humanidad blanca, que excluye a todxs Ixs otrxs que no se encajan en dichas normas, y que se manifiesta a través del discurso de odio, explotación laboral, sumisión patriarcal, misoginia, genocidios, feminicidios, exclusión y otras violencias materiales y discursivas.

Analizando esta problemática en los ámbitos del circo y de la payasaria contemporánea, observamos como la diversidad de cuerpos se ha ido borrando e invisibilizando a lo largo de la historia. Como nos explica Bolognesi (2006), la aproximación entre el circo y el teatro tiene como uno de sus conflictos básicos el enflaquecimiento del elemento épico en pro del ilusionismo dramático, la debilitación del elemento grotesco en pro de un ideal poético metafísico e intelectual:

¿No sería este un movimiento que tiende a hacer comestible a las inteligencias de las audiencias de las casas de espectáculos lo que el circo presenta y ofrece como sensorial? Las excentricidades humanas, transformadas en el circo en materia espectacular, son simplemente abolidas por cuenta de una conciencia política que no admite la existencia artística de lo diferente (Bolognesi, 2006, p.17).

Claro está que la espectacularización de lo monstruoso conforma cuestiones éticas bastante complejas, ya que hay que considerar la histórica violencia de los antiguos freak shows, minstrel shows y zoológicos humanos (Pedraza, 2009; Thomson, 1996), en los cuales innúmeros cuerpos y sujetos monstruosos eran explotados por empresarios del espectáculo y el "gran normativo público". La histórica explotación comercial de la monstruosidad en tanto espectáculo no es considerada por Bolognesi. Pero su crítica se hace relevante y contribuye al proyecto de deconstrucción del arquetipo humanista del payaso moderno, e invita a abrir un debate sobre el dilema ético en las prácticas artísticas circenses y clownescas. 
La "payasa monstruo" (Caminha, 2016) surge, en este debate, como figuración que pueda servir a un proyecto deconstructivo de la risa moderna e ilustrada, regidas por una tradición cómica humanista, colonial y patriarcal que niega la risa de la mujer y de otros cuerpos disidentes. Viene a debatir el estatuto de excentricidad otorgado a la mujer a lo largo de la historia, y proponer diálogos y contactos con otrxs cuerpxs rientes, risibles y risistentes. Intenta contribuir con el proyecto feminista de redefinir la subjetividad de la mujer, pero ahora desde las aportaciones del feminismo posthumanista y decolonial aplicado al circo y a la payasaria.

Esta figuración busca rescatar la materialidad grotesca, abyecta y monstruosa del cuerpo de las mujeres, como potencia que favorece contactos, afectos y cuidados entre diversos cuerpos, prácticas artísticas y marcos teóricos. Es una herramienta performativa y materialista que busca resignificar de forma positiva una categoría muchas veces utilizadas de manera injuriosa y denigrante: monstruo. Butler (1997) nos explica como el lenguaje injurioso puede constituirse en la condición misma de posibilidad de resistencia a través de la producción de un contra discurso originado de las posiciones subordinadas. Palabras como cunt, queer, crip ${ }^{9}$, freak, black, sudaca, entre otras, hacen parte de diversos proyectos de resistencias en el seno de diversos movimientos y teorías.

El monstruo viene recuperar el lugar de otredad que la payasa ha perdido en su itinerancia por un mundo del circo higienizado, limpio, evolucionado y humanizado, que esconde, olvida y borra, por ejemplo, sus antecedentes en los freak shows (Thomson, 1996), como las mujeres barbudas $^{10}$, por ejemplo. Performers como Jennifer Miller, del Circus Amok ${ }^{11}$, circo queer ${ }^{12}$ en Nueva York, nos hacen reflexionar y deconstruir las categorías binarias del "mundo clown", categorías binarias fijadas por el modernismo colonial e ilustrado sobre lo humano. Shayda Kafai (2010) considera que la performer y payasa ${ }^{13}$ nuevayorkina subvierte el mito de la mujer barbuda en la medida en que toma la propia barba como elemento identitario de mujer, y en que asume la propia producción artística. $\mathrm{O}$ sea, si antes las mujeres barbudas eran normalmente explotadas por familiares y empresarios en el mundo del espectáculo, bien como por científicos e intelectuales de la medicina y antropología - en tanto sujetos portadores de un conocimiento hegemónico y colonizador - , ahora la mujer con barba es autora, creadora y productora de su propia subjetividad, identidad y trabajo artístico.

La crítica general que se hace a los freak shows es de que estos se operaban para servir a la mirada normativa - the normative gaze; la mirada voyeur de la hegemonía - the voyeuristic gaze of hegemony; y aún la mirada médica y cientifica - the medical gaze, the scientific gaze. De acuerdo con estas teorías de la mirada opresora y colonizadora, aquello que es mirado es tomado como objeto a ser explotado y servir a los ojos del voyeur, del curioso, del colonizador, del médico, del científico, del intelectual, como forma de afirmar su "superioridad" intelectual, anatómica, humana, civilizatoria, o sea, como forma de garantizar su poder y hegemonía.

En Juggling Gender (1992), documental de Tami Gold sobre la vida y performance de Jennifer Miller, la artista nuevayorkina afirma que la eliminación de pelos de su cara era como una mutilación, una batalla perdida. Según Kafai (2010), la decisión de mantener la barba posiciona a Jennifer como una mujer no-normativa, que rompe con el sentido de una feminidad esencial.

Antes de fundar el Circus Amok, Jennifer Miller ha trabajado en el Coney Island Sideshow, en Brooklin, New York. En el sideshow, Jennifer trabajaba como Zenobia, la mujer barbuda que traga fuego y hace malabares. Con el personaje Zenobia, Jennifer Miller mantuvo el apodo de mujer barbuda de los freak shows. La performer explica que negociar con el arquetipo de la 
mujer barbuda le posibilitó contextualizar la figura del mito como performer. La situación es compleja, ya que Jennifer, como tantos otros performers de los freak y side shows, identifican estos espacios como los únicos dónde poder trabajar sin ser forzada a quitar la barba (Kafai, 2010).

O sea, que a pesar de la crítica que se hace a los freak shows como espacios de explotación espectacular de la diferencia corporal, del cuerpo deforme y del cuerpo crip discapacitado, es preciso tener en cuenta que muchos freaks encontraban en estos shows y circos el único ambiente en los cuales podían trabajar, vivir y sobrevivir, ya que "el mundo de fuera" del circo podía ser también un mundo muy peligroso para la salud e integridad de los freaks. De forma que también es importante considerar la comunidad que se creaba entre estos artistas y performers, que tal y como el "mundo del circo" o "mundo clown" propone, se constituye como una realidad social a parte, un "mundo al revés", regido por principios comunitarios y horizontales, aunque con sus conflictos económicos y de género, como bien apunta Mary Russo (1995).

La payasa monstruo es una figuración de múltiples pertenencias que bebe de las posibilidades de la resignificación corporal y lingüística. Reconoce su potencial visionario en las afinidades y coaliciones que puede establecer a través de una risistencia posthumana y decolonial, nutriéndose de proyectos de re-existencias a través de la risa, la comicidad y el humor.

Maldonado-Torres (2017) nos explica que el tema de la re-existencia es uno crucial en los estudios de la decolonialidad. Inicialmente planteado por el intelectual y artista colombiano Adolfo Albán-Achinte (2018), ya es parte de la pedagogía y la estética decolonial (Bento et al., 2018; Caballero, 2019; Albán-Achinte, 2009). Significa la resistencia de los pueblos que tuvieron y siguen teniendo su existencia negada. En el ámbito de la creación artística, se trata de:

...reclamar el arte como esfera (no puramente estética) de re-existencia que puede concebirse como territorio (de y para la descolonización) y que contribuye en la lucha por los territorios y por la expresión corporal en todas sus dimensiones, incluyendo en la búsqueda por el conocimiento, en la espiritualidad y en la erótica (Maldonado-Torres, 2017: s/p).

En esta dirección, un proyecto de decolonización de la risa y la payasaria también invita a recuperar las cosmovisiones sobre algunos rituales indígenas de la risa, de figuras como el "payaso sagrado" Hotxuá, de la tribu Krahô, en Tocantins, Brasil. Esto ya ha sido realizado por algunos payasos que, por ocasión del documental Hotxuá, producido por la actriz brasileña Letícia Sabatella en 2009, buscaron reaproximarse de una risa otra que no la impuesta por la comicidad europea. La película, que trata sobre la Festa da Batata, evento más importante de la tribu, habla del payaso sagrado y de la cultura de la risa existente en esta comunidad indígena. Uno de los momentos más destacados es el encuentro que hay entre el Hotxuá y el payaso Teotônio, Ricardo Puccetti ${ }^{14}$, del grupo LUME, invitado para participar de la película como forma de retratar el contraste entre estos dos tipos de payasos: el payaso sagrado y el payaso tradicional.

Aquí una política y pedagogía de risistencia monstruosa indagaría no solo por la cosmovisión indígena de la risa, pero también cómo esta concepción contribuye para decolonizar la payasaria, y cómo estas prácticas indígenas también son marcadas por la diferencia sexual en la aldea, pues los payasos sagrados son siempre los hombres de la comunidad, etc. Toda una 
problemática respecto del sistema patriarcal de la comunidad también habría que ser pensado, para no caer tampoco en una romantización de la risa tribal, sino que comprenderla y cuidarla. Tal como nos explica Rita Segato (2010), algunos sistemas indígenas, aunque patriarcales, tienen una concepción de las diferencias sexuales basadas en un sistema dual de complementariedad entre los géneros, muy diferente del sistema patriarcal moderno colonial, que entiende las diferencias a partir de un binarismo jerárquico colonial que somete las mujeres a los hombres.

Creyendo en el potencial del tránsito y del nomadismo ético de Braidotti (1994), propongo la figuración de la payasa monstruo para integrar y conectar referencias e ideas diversas que puedan deconstruir la risa humanista de la mujer y de la payasa, en lo que esta risa aún carga de continuidad de la risa patriarcal, colonial y humanista. Así pues, me atrevo a sugerir la payasa monstruo como figuración integrante del mapa de referencias que Isabel Balza (2012) propone para lo que sería un "bestiario feminista": el sujeto nómade de Rosi Braidotti (1994, 2002), el cyborg de Donna Haraway (1995), el sujeto excéntrico de Teresa de Lauretis (1993), el sujeto queer de Butler $(2001,2006)$ y el cuerpo lesbiano de Monique Wittig (1977). Balza explica cómo estas figuraciones están contribuyendo para el proyecto político del feminismo que busca replantear el sujeto del movimiento. Yo también añadiría a su lista el bestiario propuesto por las feministas de la diferencia sexual, a través de las siguientes creaciones: el cuerpo maternal abyecto de Julia Kristeva (1980), la medusa de Hélène Cixous (1975), el sexo que no es uno de Luce Irigaray (2009).Todas estas autoras, aunque difieren en posicionamientos y planteamientos importantes en el debate esencial-construido, natural-nutrido, biologíacultura, políticas identitarias y posidentitarias, todas ellas dibujan un imaginario relacionado a la figura del monstruo.

Pero un proyecto de bestiario feminista no puede pensar solo cuerpas blancas monstruosas. Otras mujeres monstruosas inapropiadas también hacen parte del bestiario, aunque con diversos niveles de marginalidades situadas geo-política-colonialmente. Estas mujeres monstruosas inapropiadas ya han sido paridas por las feministas de color, chicanas, mujeres tercermundistas y feministas decoloniales, en figuraciones tales como: la mestiza de Gloria Anzaldúa (1999), la subalterna de Gayatri Spivak (1988), la mujer del Tercer Mundo de Chela Sandoval (2000), la Amefricaladina de Lélia González (1988a, 1988b), entre otras tantas.

El feminismo negro y las teóricas decoloniales han contribuido para replantear el movimiento feminista desde dentro, denunciando la falsa universalización y solidaridad del feminismo blanco, insistiendo que el género no puede ser nunca considerado como categoría opresora por sí sola. Que las categorías de clase, etnia, procedencia geográfica, religión y procesos de racialización también han de ser llevadas en cuenta a la hora de configurar la subjetividad de los sujetos, bien como la opresión de las mujeres. De forma que todas estas categorías y procesos deben ser analizados en su entrecruce, siguiendo una política de interseccionalidad que indague sobre la especificidad de la diferencia de cada mujer (Hooks, 1982; Hooks et al., 2004; Collins, 2000; Vigoya, 2016; Crenshaw, 1995; Lugones, 2011).

Yuderkis Espinosa-Miñoso convoca a una desobediencia epistémica, para tal de producir y visibilizar las experiencias de las diversas mujeres colonizadas, explicando sus propias visiones e interpretaciones del mundo, como tarea prioritaria de los procesos de descolonización. "Una tarea que debe estar acompañada de procesos de recuperación de las tradiciones del saber que en Abya Yala han resistido al embate de la colonialidad, así como aquellas que desde otras geografías y desde posiciones críticas han contribuido a la producción de fracturas 
epistemológicas" (2014, p.8).

La payasa monstruo es una figuración que nace a partir del feminismo posthumano, pero que también bebe del feminismo decolonial, ya que indaga por diversas otredades y experiencias coloniales de la risa. Pero para esto, hay que preguntarse primero cómo se construyen Ixs sujetxs colonizadxs, historizarlos y contextualizarlos geo-cuerpo-políticamente, para después preguntarse, qué significa descolonizar la payasaria en la práctica, qué aporta la payasaria para la decolonización del cuerpo, y qué dimensión crítica y relevancia política adquiere para resignificar la risa.

Si nos fijamos en la historia del circo y la payasaría, las pocas referencias que tenemos sobre los cómicos de color son Chocolat, en el ámbito del circo, bien como los black faces de los minstrel shows americanos. Footit y Chocolat hacían un dúo de payasos. Footit era el clown blanco y Chocolat, el payaso augusto. Los tradicionales gags, slapsticks y comedia física elaborada por el dúo siempre acaban con Chocolat Ilevando bofetadas. La relación de dominación, poder y autoridad que siempre se ha establecido entre las tipologías blanco y augusto se evidencia en esta dupla como representación de la dominación colonial. Los minstrel shows, por su vez, también han contribuido para construir un estereotipo del negro como encarnación del Otro, exótico, incivilizado, inferior. También los coons se han constituido como arquetipos de una comicidad negra que estereotipaba el negro de forma muy denigrante, como el animal, inculto, perezoso (Towsen, 1996; Bogle, 1992).

Una cosa es que las tipologías de clown blanco y augusto jueguen con la cuestión de la autoridad, del poder y de la dominación entre performers blancos, que usen la máscara blanca para reforzar la blancura en tanto símbolo de poder entre blancos. Un juego que se configura como uno de los pilares mismo de la poética del payaso moderno. El cara blanca, encarnación del orden, de la moral, de la higiene y de la autoridad, somete al payaso augusto. Este, al llevar el maquillaje rojo en la cara, hace referencia a la vulnerabilidad del sufrimiento, de las lágrimas, de la risa incontrolable, de las travesuras que calientan y deja la piel roja. Pero cuando estas tipologías son encarnadas entre performers blancos y negros, y/o entre audiencia blanca y performers de color, toda una problemática relacionada con la dominación colonial emerge en la payasaria y el circo.

Pero, aunque los estudios postcoloniales se hayan ocupado bastante en analizar la representación y la construcción del Otro negro como Otro exótico, animalizado y aculturado, la payasaria aún no se ha ocupado de tal empresa, imprescindible para reconocer los límites de su risa ilustrada humanista eurocéntrica. Así que se nos hace necesario rescatar referencias de cómicxs y payasxs negros y de color, bien como desarrollar una mirada interseccional y decolonial sobre el circo y payasaria contemporáneas.

En esta dirección, nos hace falta visibilizar las historias de payasxs negros, como Benjamim de Oliveira, el primer payaso negro de Brasil $^{15}$, homenajeado este año por la escuela de samba Salgueiro. También la historia de Maria Eliza ${ }^{16}$, payaso Xamego, que a principios de los años 40 y 60 fue el gran atractivo del Circo Guarany, en Brasil. Además de referencias históricas como estas, también artistas negrxs contemporáneos que trabajan con el objetivo de descolonizar el cuerpo a través de la payasaria, como Felícia de Castro ${ }^{17}$ y el colectivo Trupe Liuds ${ }^{18}$.

Además de una larga trayectoria como actriz y payasa, Felícia de Castro lleva años realizando un curso de payasas para mujeres, sean o no artistas, ya que se trata en realidad de una vivencia para 
rescatar el sentido cómico del cuerpo en relación con la naturaleza y la madre tierra. La vivencia Palhaças, bem vindas sois vós! ${ }^{19}$ trabaja dentro de una perspectiva decolonial y ecológica que rescata mucho de las tradiciones femeninas y feministas, de cura y de cuidado, así como de exploración de la sensualidad, sexualidad y erotismo. Trabajando con mitos como la Baubo y autoras como Audre Lorde, Felícia busca rescatar referencias ancestrales y contemporáneas.

Nuestro acto político es el coraje para enfrentar nuestro interior; decolonizar este cuerpo y ser quienes somos en la máxima potencia. Subvertir el orden. Así entiendo la payasaria femenina y reflexiono sobre el papel de nuestros cuerpos y de nosotras como mujeres en nuestras prácticas políticas, artísticas y espirituales. (...) Esta rueda de payasaria femenina desafía, con una gran carcajada, que proviene de nuestra vulva, este sistema patriarcal, sexista, capitalista, inhumano y racista (...) Resurgimos como Diosas de la Risa, resurgimos del subterráneo salvaje, de nuestras naturalezas, de debajo de la tierra. Somos las diosas sucias. Esta es la payasa sagrada que he estado buscando en mí (Castro, 2019, p.28).

La Trupe Liuds, por su vez, es un colectivo de payasos y payasas negras, también de Brasil. En lugar de la nariz roja, llevan la nariz negra ${ }^{20}$. El espectáculo Mjiba, a boneca guerreira ${ }^{21}$, cuenta la historia de dos payasos carteros que encuentran algo totalmente inesperado en un paquete sin dirección de pedido ni retorno. Se trata de una muñeca negra llamada Mjiba. A partir de este descubrimiento, presentan y discuten de manera lúdica los problemas que enfrentan las mujeres negras en la sociedad, haciendo un homenaje a las luchas de las mujeres negras. La Trupe Liuds también tiene un curso titulado Comicidade Negra, que busca, a través de técnicas de la payasaria, decolonizar el cuerpo negro.

Ejemplos como Jennifer Miller, Felícia de Castro, TrupeLiuds y el payaso sagrado Hotxuá nos invitan ir más allá de los arquetipos payasos y payasas, engendrados según los dictados de la modernidad colonial humanista. En esta dirección, propongo pensar en la idea del transclown, clownqueer, cripclown, coloredclown, indigenous clown, rainbown clowns: payasxs que, aunque diferenciados geo-cuerpo-histórica-políticamente, guardan estrategias paródicas y existencias cómicas similares, pero que se encuentran marginalizadxs de los circuitos oficiales de la cultura y del arte, así como del imaginario cómico patriarcal, blanco, humanista, colonial, antropocéntrico y heteronormativo.

La payasa monstruo es la madre desviada de todxs Ixs sujetxs cómicxs que no se encajan en las variaciones de género del mundo payaso y su "gran y respetable público". Sus hijxs son los cuerpos mutantes, fluidos y plásticos que ríen de sí mismos y de la concepción humanista y colonial que jerarquiza, excluye, esclaviza y mata. Son los cuerpos excéntricos de las "payasas mujeres y mujeres payaso" (Caminha y Pagès,2017), Drag Queens y Drag Kings (Butler, 2001; Halberstam, 1998; Muñoz, 1999), bufonas, enanos, mujeres barbudas, gigantes, deformes, tullidos, freaks (Thomson, 1996), coons (Bogle, 1992), cómicos gays, lesbianas, transexuales y otrxs cuerpxs y formas paródicas: las "multitudes queer" (Preciado, 2003), dueñas de una risa potencialmente transformadora de miradas y afectos.

Una comicidad monstruosa desea devolver a la payasaria de las mujeres no solo el elemento grotesco, sino también construir espacios de co-creación de contactos, cuidados, afectos y risas entre y con Ixs sujetxs que están al margen, en el umbral, en los límites de la humanidad. En este sentido, payasos y payasas dejan de pretender representar la humanidad en su afán ilustrado de progreso y evolución. 
Es importante aclarar que tales figuraciones no tienen como objetivo poner Ixs diversos cuerpos y prácticas risistentes bajo el paraguas de la payasaria, sino permitir una aproximación, afectos y alianzas entre diversxs sujetxs rientes y risibles. Tales figuraciones buscan, por tanto, to queer, to crip, to color and decolonize the clown, es decir, sacar el clown del egocentrismo y endogamia presente en sus prácticas performativas, pedagógicas y políticas. También desean ampliar la mirada de públicos diversos, y proponer alianzas políticas estratégicas entre artistas de la risa y la comicidad. Clownqueers, transclowns, cripclowns, colored clowns, indigenous clowns and rainbown clowns no serían solamente una posibilidad híbrida de artista trans-wo/man-cripqueer-colored-indigenous-clown, pero principalmente verbos que convocan alianzas, cuidados y debates sobre la ética de la risa, que también lleve en cuenta los entrecruces de las marcas de la diferencia corporal que excluyen Ixs sujetxs desterrados del concepto de humano.

\section{CONSIDERACIONES FINALES}

La payasaria contemporánea empieza a reinventarse a finales del siglo pasado, con el movimiento de payasas mujeres de las últimas décadas. A principio bastante enfocado en la categoría "comicidad femenina", supuestamente vinculada a una esencia biológica y universal, el movimiento empieza una deriva reciente hacía una "comicidad y payasaria feminista". De este movimiento surgen innúmeros proyectos de visibilización y fomento de la figura de la payasa, a través de festivales, cursos, encuentros, publicaciones, performances y espectáculos. España y Brasil lideran el movimiento de payasas, pero en otros países también empiezan a abrazar este fenómeno, tanto en el ámbito académico como artístico y cultural, principalmente en Latino América. Esta payasaria femenina y/o feminista, sin embargo, aún se encuentra enganchada en la lógica del arquetipo humanista del payaso moderno. Una lógica que también esconde tropos coloniales.

Para que las payasas mujeres puedan avanzar en sus políticas del cuerpo, se hace necesario indagar más allá del sexo y género, incorporando la pregunta por lo humano y lo monstruoso. Una indagación decolonial y posthumana capaz de rescatar los saberes del sur, conocimientos y cosmovisiones indígenas, negras, mestizas, además de dialogar con perspectivas teóricas queer y crip. Las payasas han llegado para deconstruir el arquetipo humanista del payaso moderno, y rescatar imaginarios, saberes y conocimientos situados, interseccionales, abyectos, grotescos, monstruosos.

En el mundo de la payasaria, se hace necesario un análisis de lo que sería una risa abyecta, risa monstruosa, risa feminista, risa postcolonial, risa negra, risa queer, risa crip, risa trans, risa pobre, risa indígena. La payasa monstruo y sus hijxs desterrados emergen con un fuerte potencial para abrir las puertas para una risa crítica y una payasaria alternativa, donde los personajes y personas cómicas puedan ir más allá de su humanidad ilustrada, rescatando performances, discursos, afectos, amores e imaginarios monstruosos. Un proyecto que invita a celebrar y problematizar nuestras risistencias monstruosas. 


\section{REFERENCIAS}

Albán-Achinte, A. (2018). Prácticas creativas de re-existencia: más allá del arte...el mundo de lo sensible. Madrid: Traficantes de Sueños.

(2009). Pedagogías de la re-existencia. Artistas indígenas y afrocolombianos. En W. Mignolo y Z. Palermo (comps), Arte y estética en la encrucijada descolonial (pp. 443468). Buenos Aires: Ediciones del Signo.

Anzaldúa, G. (1999). Borderlands / la frontera: the new mestiza. San Francisco: Aunt Lute Books.

Aristóteles (1994). Reproducción de los animales. Madrid: Gredos.

Bakhtin, M. (2002). A cultura popular na Idade Média e no Renascimento. O contexto de François Rabelais. São Paulo: Annablume.

Balza, I. (2012). Crítica queer y sujetos (monstruosos) del postfeminismo.Arte, educació y cultura: Aportaciones desde la periferia. Jaén: COLBAA.

Bento, K., Ruiz Ponce, H., Sempertegui, A. y Di Paolo, L. (2018). Diálogos de (re)existencia Indígena AfroLatinxs: descolonialidadesposibles. Alternautas - (Re) SearchingDevelopment: The AbyaYalaChapter. (Online Journal). Recuperados de http://www.alternautas.net/ blog/2019/4/26/dialogos-de-reexistencia-indigena-afro-latinxsdescolonialidades-posibles/y https://static1.squarespace. com//5362250de4b0e6ed7cf86ed1/t/5e62e318f25d2344a69c0d cc/1583538970471/6.1.3.pdf

Bergson, H. (2004). O riso: ensaio sobre a significação da comicidade. São Paulo: Martins Fontes.

Bogle, D. (1992). Tooms, coons, mulattoes, mammies and bucks: an interpretive history of blacks in American Films. New York: The Continuum Publishing Company.

Bolognesi, M. F. (2003). Palhaços. São Paulo: UNESP. (2006). Circo e teatro: aproximações e conflito. Revista Sala Preta, 6, 9-19, São Paulo: USP.DOI: https://doi. org/10.11606/issn.2238-3867.v6i0p9-19 
Braidotti, R. (1994). Nomadic subjects: embodiment and sexual difference in contemporary feminist theory. New York: Columbia University Press.

y Lykke, N. (Ed.) (1996). Between monsters, goddesses and cyborgs: Feminist confrontations with science, medicine and cyberspace. London:ZedBooks.

(2002). Metamorfosis: hacia una teoría materialista del devenir. Madrid: Akal.

(2013). The posthuman. Cambridge, UK: Polity Press.

y Hlavajova, M. (Ed.) (2018). Posthuman glossary.

London: Bloomsbury.

Burnier, L.O. (2001). A arte de ator: da técnica a representação. São Paulo: UNICAMP.

Butler, J. (1997). Excitable speech: the politics of the performative. New York and London: Routledge.

(2001). El género en disputa: el feminismo y la subversión de la identidad. Barcelona: Paidós.

(2006). Deshacer el género. Barcelona: Paidós.

Caballero, B.R. (2019). Mujeres creando. El cuidado como maniobra ecológica de re-existencia. Arte y Políticas de Identidad, 21, 74-95.

Caminha, M. L. (2006) O riso no clown: sentido político en la poética de Bertolt Brecht. Trabajo de fin de grado no publicado. Curso Superior de Tecnologia em Artes Cênicas. Centro Federal de Educação, Ciência e Tecnologia do Ceará (CEFET-CE).

Caminha, M. L. (2016) Payasas: historias, cuerpos y formas de representar La comicidad desde uma perspectiva de género. Tesis doctoral no publicada. Disponible en: http://diposit. ub.edu/dspace/handle/2445/106705/

Caminha, M. L., y Pagès, J. V. (2017) Payasas mujeres y mujeres payaso: el travestismo en la payasaria. Visualidades, 15(1), 143170. Disponible en: https://doi.org/10.5216/vis.v15i1.48278

Castro, F. (2019). O riso que habita o ventre da terra. Palhaçaria pessoal numa perspectiva femenina, feminista, ritualística, 
política e selvagem. Palhaçaria Femenina, 28,26-29.

Cardoso, C.P. (2014). Amefricanizando o feminismo: o pensamento de Lélia Gonzalez. Revista Estudos Feministas, 22(3), 965-986.

Cixous, H. (1975). La sonrisa de la Medusa. Ensayos sobre la escritura. Barcelona: Anthropos.

Collins, P.H. (2000). Black feminist thought: knowledge, consciousness and the politics of empowerment. New York and London: Routledge.

Crenshaw, K. (1995). Mapping the margins: intersectionality, identity politics, and violence against women of color. Recuperado de https://www. racialequitytools.org/resourcefiles/mapping-margins.pdf

Davis, N. Z. (1978). Women on top: symbolic sexual inversion and political disorder in early modern Europe. En: Babcock, B. y Turner, V. (Ed.) Reversible World: symbolic inversion in art and society (symbol, myth and ritual). Ithaca (NY), London, Cornell University Press.

Espinosa-Miñoso, Y. (2014). Una crítica descolonial a la epistemología feminista crítica. El Cotidiano, 184, 7-12.

Ferracini, R. (2003). A arte de não interpretar como poesia corpórea do ator. São Paulo: UNICAMP.

Fink, I. (1967). Karandash. En The soviet circus: a collection of articles, (pp. 6171). Moscow: Progress Publishers.

González, L. (1988a). A categoria político-cultural de amefricanidade. Tempo Brasileiro, 92/93, 69-82.

(1988b). Por un feminismo afrolatinoamericano. Isis Internacional \& MUDAR - Mujeres por un Desarrollo Alternativo. Mujeres. crisis y movimiento. América Latina y el Caribe, 9, s/p. Ediciones de las Mujeres.

Green, M. y Swan, J. (1986). The triumph of pierrot: the commedia dell'arte and modern imagination. New York: Macmillian Publishing Company.

Halberstam, J. (1998). Female masculinity. Londres: Durk University Press University Press.

Haraway, D. (1995). Ciencia, cyborgs y mujeres: la reinvención de la naturaleza. Madrid: Cátedra.

Hooks, B. (1982). Ain't I a woman? London: Pluto Press. 
Hooks, B., Brah, A., Sandoval, C., Anzaldúa, G., Morales, A. L., Bhavnani, K. K., Coulson, M., Alexander, J. M. y Mohanty, C. T. (2004) Otras inapropiables: feminismos desde las fronteras. Madrid: Traficantes de sueños.

Irigaray, L. (2009). Ese sexo que no es uno. Madrid: Akal.

Jara, J. (2007). El clown, un navegante de las emociones. Sevilla: PROEXDRA - Asociación de Profesores por la Expresión Dramática en España.

Junqueira, M.R. (2012). Da graça ao riso: Contribuições de uma palhaça sobre a palhaçaria feminina. Disertación de máster no publicada. Universidade Federal do Estado do Rio de Janeiro.

Kristeva, J. (1980). Poderes de la perversión. México: Siglo XXI.

Lecoq, J. (2009). El cuerpo poético: una pedagogía de la creación teatral. Barcelona: Alba Editorial.

Lugones, M. (2011) Hacía um feminismo descolonial. La manzana de la discordia, 6(2), 105-119.

Maldonado-Torres, N. (2017). El arte como territorio de reexistencia: una aproximación decolonial. Iberoamérica Social: revista-red de estudios sociales VIII, $26-28$. Recuperado de https://iberoamericasocial.com/arte-territorio-re-existencia-unaaproximacion-decolonial/

McRuer, R. (2006). Crip Theory: Cultural Signs of Queerness and Disability. New York: New York University Press.

Muñoz, J.E. (1999). Disidentifications: queers of colors and the performance of politics. Minneapolis, London: University of Minnesota Press.

Nascimento, E.C.M. (2014).Comicidade feminina: as possibilidades de construção do cômico no trabalho de mulheres palhaças. Disertación de máster no publicada. Universidad Federal de Bahia.

Nash, J. C. (2019). Black feminism reimagined: After intersectionality. Durham and London: Duke University Press.

Pavis, P. (2005). Dicionário de teatro. São Paulo: Perspectiva.

Pedraza, P. (2009). Venus barbuda y el eslabón perdido. Madrid: Siruela. 
Popov, O. (1967). My hero. The soviet circus: a collection of articles, 39-60. Moscow: Progress Publishers.

Preciado, B. (2003). Multitudes queer: notas para una política de los anormales. Revista Multitudes, 12, 157-166. Recuperado de https://revistas.unc.edu.ar/index.php/NOMBRES/article/ view/2338

Propp, V. (1992). Comicidade e riso. São Paulo: Ática.

Puccetti, R. (2005) O riso dos Hotxuá. ILINX - Revista do LUME, 6, 109-115. Recuperado de http://www.cocen.unicamp.br/ revistadigital/index.php/lume/index

Quijano, A. (2014). Colonialidad del poder, eurocentrismo y América Latina. Cuestiones y horizontes: de la dependencia histórico-estructural a la colonialidad/descolonialidad del poder. Buenos Aires: CLACSO. Recuperado de http://biblioteca.clacso. edu.ar/clacso/se/20140507042402/eje3-8.pdf

Rich, A. (1984). Notes towards a politics of location. Blood, Bread, and Poetry: Selected Prose 1979-1985, 210-232. New York: W. W. Norton.

Russo, M. (1995). The female grotesque. Risk, excess and modernity. New York and London: Routledge.

Saavedra, R. F. (2011). Mulheres palhaças: a poética e a política da comicidade feminina. Monografía de graduación no publicada. Universidade Federal do Rio de Janeiro.

Sandoval, C. (1991). U.S. Third World Feminism: The Theory and Method of Oppositional Consciousness in the Postmodern World. Genders, 10, 1-24.

Santos, S.M. (2014). Mulheres palhaças: Percursos históricos da palhaçaria feminina no Brasil. Disertación de máster no publicada. Universidade Estadual Paulista.

Segato, R.L. (2010). Colonialidad y género: en busca de claves de lectura y de un vocabulario estratégico descolonial. (s/p). Recuperado de https://nigs.ufsc.br/files/2012/09/genero_y_ colonialidad_en_busca_de_claves_de_lectura_y_de_un_ vocabulario_estrategico_descolonial_ritasegato.pdf

Silva, E. (2007). Circo-Teatro: Benjamim de Oliveira e a teatralidade circense no Brasil. São Paulo: Editora Altana. 
Sousa, L.P.Q. y Pessoa, R.R. (2019). Humans, nonhuman others, matter and language: a discussion from posthumanist and decolonial perspectives. Trabalhos em Linguística Aplicada, 58(2), 520-543. DOI: https://doi.org/10.1590/010318135373715822019

Spivak, G.C. (1988). Can the subaltern speak? En Marxism and the interpretation of culture, (pp. 271-313). Macmillan Education: Bassingstoke.

Sussman, M. (1998). Queer circus: Amok in New York. En Radical street performance: an international anthology, (pp. 262-270). New York: Routledge.

Thomson, R.G. (Ed.) (1996). Freakey: Cultural spectacles of the extraordinadry body. New York: University Press.

Towsen, J. (1976). Clowns. New York: Hawthorn Books.

Turner, V. (1982). From ritual to theatre: the human seriousness of play. New York: PAJ Publications.

(1988). The ritual process: Structure and anti-structure.

Madrid: Taurus.

Vigoya, M.V. (2016). La interseccionalidad: una aproximación situada a la dominación. Debate Feminista, 52, 1-17. Recuperado de https://reader.elsevier.com/reader/sd/pii/S01889478163006 03?token $=53755 F A 37 B 7 B 5646882 F A 1 E 4 C 0 E 576 F 8 D 13 C 4 C 785 C$ 86F590691F2E519E0C1D73A6A8C85156CB7C2F9960CE1B9913A $6 A C$

Wiles, D. (1987). Shakespeare's clown: Actor and text in the Elizabethan playhouse. Cambridge: University Press.

Winnubst, S. (2018). Decolonial critique. En: R. Braidotti, y M. Hlavajova, (Eds.). Posthuman glossary, (pp. 97-99). London and New York: Bloomsbury Academic. 
1. Para saber más, recomiendo consultar la web de la plataforma internacional sobre investigación en artes circenses CARP: https://www.circostrada.org/en/news/membersnews-worldwide-platform-circus-arts-research/

2. Circus and Its Others es una conferencia bienal internacional des de 2016. En 2020, estarán celebrando la tercera edición: https://www.circusanditsothers.org/about-caio-2020/

3. Los "doctores payasos" son hoy muy presentes en espacios sanitarios y terapéuticos de diversos países en Europa y América, especialmente Brasil, España y Estados Unidos.

4. Para saber más sobre las diferentes corrientes y perspectivas relacionados al posthumanismo, tales como transhumanismo, crítica decolonial, afrofuturismo, antropoceno, nuevos materialismos y otros conceptos y perspectivas relacionadas, consultar: Braidotti y Hlavajova, 2018.

5. Todas las traducciones al español, en este trabajo, han sido realizadas libremente por la autora, de las versiones originales en inglés y portugués, que se encuentran en la bibliografía final.

6. La expresión "gran y respetable público" es muy utilizada en Brasil para recibir y dar la bienvenida a los espectadores del circo.

7. Para construir su teoría sobre colonialidad del género, Lugones se inspira en el trabajo de Aníbal Quijano (2014) sobre la colonialidad del poder.

8. Abro un paréntesis para explicar brevemente que lo queer en el Sur Global es enunciado de múltiples formas, diferentes al queer del norte global. Estas enunciaciones otras de lo que sería lo queer en el sur también debe ser problematizada en un proyecto decolonial en el circo y la payasaria, que hay que atender a las diferentes onto-epistemologías, a fin de complejizar las relaciones de poder en la producción de conocimiento de esa teoría que viene impuesta desde el norte. Pero esto es un tema para seguir profundizando en otro trabajo.

9. Para saber más sobre la relación entre las teorías queer y crip, consultar: McRuer (2006).

10. Para una explicación divertida del mito de la mujer barbuda, ver el programa Arte con Mayúsculas, número 3, dedicado a las mujeres barbudas. En el programa, las presentadoras Svaselina Luvrika y Martina Dry hacen un recorrido histórico del mito, y también mencionan los nombres de varias mujeres con barba, artistas contemporáneos como la española Plastika y Toyota. Disponible en youtube: https://www.youtube.com/ watch?v=VhRNYTilz-U/

11. http://www.circusamok.org/

12. Para saber más sobre la queeridad del Circus Amok, consultar: Sussman (1998). 
13. En una cita inicial, Shayda Kafai se refiere a Jennifer Miller como clown (Kafai, 2010).

14. Para un análisis de la risa del payaso sagrado a los ojos del actor Ricardo Puccetti, consultar O Riso do Hotxuá, (Puccetti, 2005).

15. Para saber más sobre la historia del primer payaso negro de Brasil, consultar: Silva, 2007.

16. En 2016, Ana Minehira y Mariana Gabriel estrenan un documental sobre la vida de la artista. La película destaca la influencia de los negros en el espectáculo del circo y los prejuicios que sufrieron en este medio. Para la realización de la película, un equipo se dedicó durante dos años a rescatar la historia de esta mujer payasa que cuidó a sus hijos en los camerinos y, en la arena, vitoreó y sedujo al público con sus bromas, chistes, divertidos musicales, perros y gatos entrenados.

17. Perfil de Felícia en Instagram: https://www.instagram.com/feliciadecastroartist/

18. Perfil de la TrupeLiuds en Instagram: https://www.instagram.com/ciatrupeliuds/

19. Página del curso impartido por Felícia en facebook: https://www.facebook.com/ palhacasbemvindassoisvos/

20. Considero este acto simbólico de suma importancia, ya que la nariz roja del payaso moderno marca la vulnerabilidad de la piel blanca, pero no da cuenta de la vulnerabilidad de la piel negra. La nariz como símbolo del clown moderno, así como la relación de la payasaria negra contemporánea con los black faces, constituyen una gran y complexa problemática que escapan al objetivo de este artículo, pero que siguen como parte del proyecto de decolonizar la risa, la payasaria y el circo.

21. Reportaje del periódico Folha de São Paulo sobre la TrupeLiuds:

https://mural.blogfolhauol.com.br/2019/06/17/de-perus-a-africa-trupe-liuds-levaespetaculo-sobre-mulher-negra-para-mocambique/ 